UC-20D

WFPS : TME-79-015

MARCH 1979

\title{
ANALYSIS OF A WATER MODERATED CRITICAL ASSEMBLY WITH ANISN-VITAMIN C
}

L. GREEN

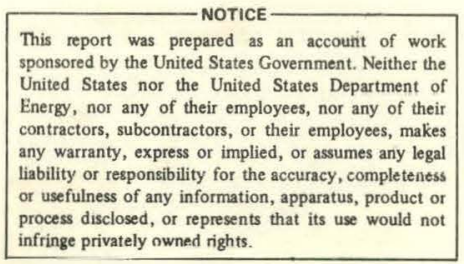

fusion power

systems department

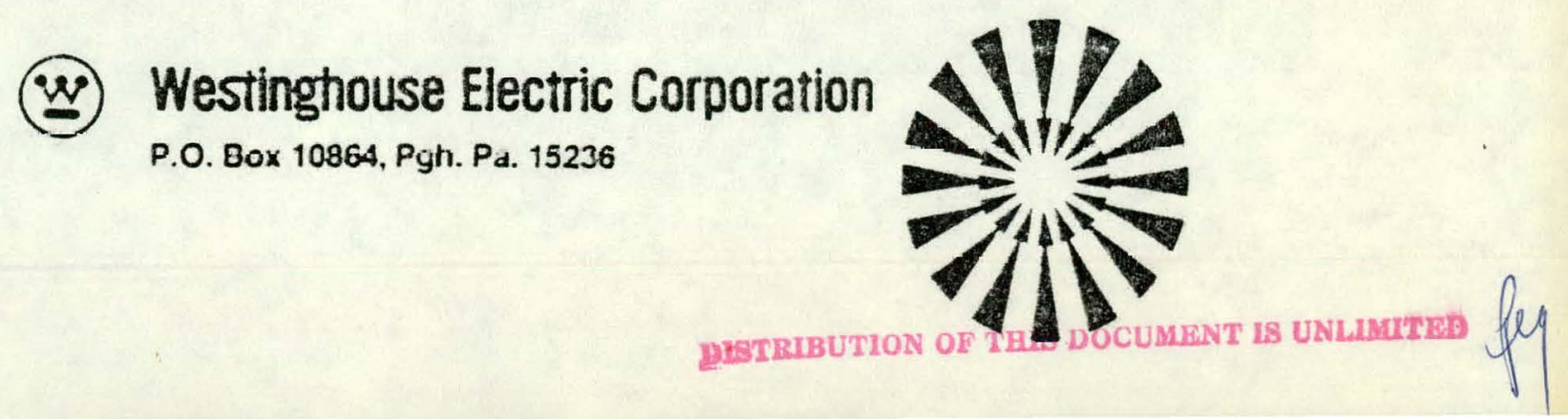




\section{DISCLAIMER}

This report was prepared as an account of work sponsored by an agency of the United States Government. Neither the United States Government nor any agency Thereof, nor any of their employees, makes any warranty, express or implied, or assumes any legal liability or responsibility for the accuracy, completeness, or usefulness of any information, apparatus, product, or process disclosed, or represents that its use would not infringe privately owned rights. Reference herein to any specific commercial product, process, or service by trade name, trademark, manufacturer, or otherwise does not necessarily constitute or imply its endorsement, recommendation, or favoring by the United States Government or any agency thereof. The views and opinions of authors expressed herein do not necessarily state or reflect those of the United States Government or any agency thereof. 


\section{DISCLAIMER}

Portions of this document may be illegible in electronic image products. Images are produced from the best available original document. 
WFPS: TME-79-015

MARCH 1979

\section{FUSION POWER SYSTEMS TECHNICAL NOTE}

\section{ANALYSIS OF A WATER MODERATED CRITICAL ASSEMBLY WITH ANISN-VITAMIN C}
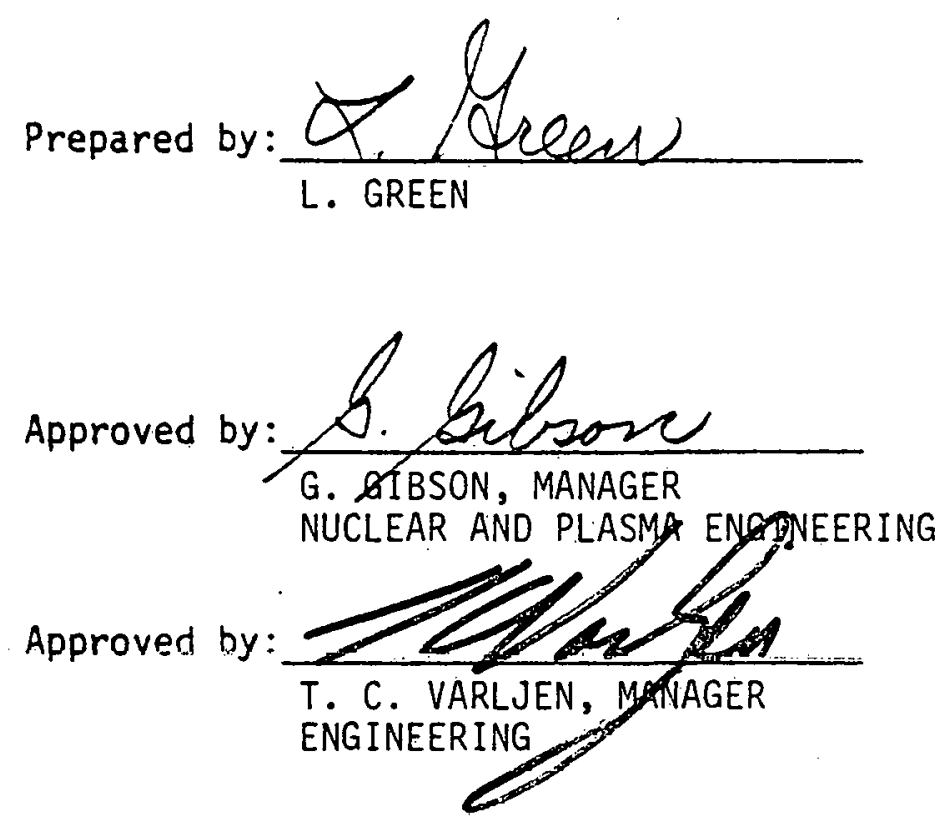

\section{fusion pouses systems deportment}

(4y) Westinghouse Electric Corporation P.0. Box to864. Pgn. Ps. 15236

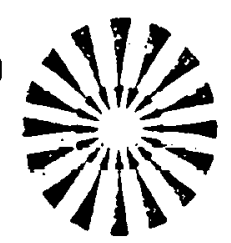




\section{ACKNOWLEDGEMENT}

This work was performed for the Office of Fusion Energy of the U.S. Department of Energy under Contract EG-77-C-02-4544. Reproduction, translation, publication, use and disposal, in whole or in part, by or for the United States Government is permitted.

\section{LEGAL NOTICE}

This report was prepared as an account of Government sponsored work. Neither the United States, nor the Department of Energy, nor any person acting on behalf of the Department:

A. Makes any warranty or representation, expressed or implied, with respect to the accuracy, completeness, or usefulness of the information contained in this report, or that the use of any information, apparatus, method or process disclosed in this report may not infringe privately owned rights; or

B. Assumes any liabilities with respect to the use of, or for damages resulting from the use of any information, apparatus, method, or process disclosed in this report.

Printed in the United States of America Available from

National Technical Information Service U. S. Department of Commerce 5285 Port Royal Road Springfield VA 22161

Price:Printed Copy $\$ 4.00$; Microfiche $\$ 3.00$ 


\section{ABSTRACT}

A tightly packed water moderated ${ }^{233} \mathrm{UO}_{2}-\mathrm{ThO}_{2}$ critical assembly was analyzed with the Vitamin $C$ library and the 1-D $S_{n}$ code, ANISN $\left(S_{8}, P_{3}\right)$. The purpose of the study was to provide validation of this calculational model as applied to water-cooled hybrid fusion blankets. The quantities compared were the core eigenvalue and various activation shapes.

The calculated eigenvalue was $1.02 \pm 0.01$. The ${ }^{233} \mathrm{U}$ fission and ${ }^{232}$ Th capture shapes were found to be in good agreement $( \pm 5 \%)$ with experiment, except near water-metal boundaries where differences up to $24 \%$ were observed. No such error peaking was observed in the ${ }^{232}$ Th fast fission shape.

We conclude that the model provides good volume averaged reaction rates in water-cooled systems. However, care must be exercised near water boundaries where thermally dependent reaction rates are significantly underestimated. 
TABLE OF CONTENTS

Page No.

1.0 INTRODUCTION

$1-1$

2.0 THE BMU-TA CORE 2-1

3.0 CALCULATIONAL MODEL 3-1

3.1 CROSS SECTION GENERATION 3-1

3.1.1 SEED REGION 3-1

3.1 .2 BLANKET REGION 3-1

3.1 .3 INNER AND OUTER METAL WATER REGIONS 3-1

$\begin{array}{lll}4.0 & \text { TRANSPORT CALCULATION }\end{array}$

5.0 RESULTS 5-1

5.1 CORE EIGENVALUE $5-1$

5.1.1 MESH SPACING 5-1

5.1 .2 INPUT BUCKLING $5-1$

5.1 .3 GEOMETRY $5-2$

5.1 .4 FISSION SPECTRUM $5-2$

5:2 CORE ACTIVATION SHAPES $5-2$

6.0 SUMMARY AND CONCLUSIONS 6-1

$\begin{array}{lll}7.0 & \text { REFERENCES }\end{array}$ 


\section{LIST OF FIGURES}

Figure No.

Page No.

2-1 BMU-1 Side View.

$2-2$

2-2

BMU-1A One-Sixth Core Top View.

$2-3$

3-1

Calculational Model

$3-2$

$3-2$

Seed Rod Group.

$3-4$

$3-3$

Blanket Rod Group.

$3-5$

$3-4$

Simulated Fu11 Core Geometry.

$3-6$

5-1 Comparison of Measurement and Calculation for 233 fission.

5-2 Comparison of Measurement and Calculation for Thorium Capture.

$5-4$

$5-5$

5-3 Comparison of Measurement and Calculation for Thorium Fission.

$5-6$ 


\section{LIST OF TABLES}

Table No.

2-1 BMU-TA PELLET AND ROD DIMENSIONS

2-2 BMU-1A FUEL ROD COMPOSITIONS

2-3 COMPARISON OF DTHR AND BMU-TA

$3-1$

27 ENERGY GROUP STRUCTURE
Page No.

$2-4$

$2-5$

$2-6$

$3-3$ 


\subsection{INTRODUCTION}

The Vitamin C. library (1), packaged by the Radiation Shielding Information Center (RSIC) as DLC-41, is a coupled 171 neutron, 36 gamma-ray-group library based on ENDF/B-IV ${ }^{(2)}$. It was issued in 1976 and intended primarily for fast reactor (LMFBR) core and shield analyses and fusion neutronics applications. Indeed, the validation effort proposed for the library stressed integral experiments in pure fusion blanket and shield materials. This intent is reflected in the weight functions used to obtain the 171 neutron group cross sections from ENDF/B-IV, and in the absence of thermal scattering matricies for the common moderator materials (water, graphite, polyethylene). As a consequence, calculations for systems containing appreciable amounts of any of these materials must be approached with caution.

In the investigation of the fusion-fission hybrid concept a variety of blanket configurations have been considered, including both water $(3,4)$ and steam-cooled $(5)$ systems. For typical fuel and coolant volume fractions, the thermal group ( $E<0.4 \mathrm{eV}$ ) absorption fractions varied from $35 \%$ to $60 \%$, with corresponding resolved resonance absorptions ( $E<5.5 \mathrm{keV}$ ) of $35 \%$ and $24 \%$. These values are sufficiently large so that validation of Vitamin $C$ in describing the neutronics behavior of such systems is important.

In the present work, a tightly packed, water moderated ${ }^{233} \mathrm{UO}_{2}-\mathrm{ThO}_{2}$ critical assembly operated at the Bettis Atomic Power Laboratory (BAPL), and designated as BMU-1A ${ }^{(6)}$, was analyzed utilizing the Vitamin $C$ library and the ANISN ${ }^{(7)}$ transport code. The core consisted of a single hexagonally symmetric seed and blanket, with fuel and water volume fractions close to those for a typical water-cooled hybrid blanket. It was therefore expected that analysis of the BMU-TA experiment would provide a good test of the Vitamin C library for application to blankets with significant thermal and epithermal neutron absorptions. 


\subsection{THE BMU-TA CORE}

The BMU-IA was one of a series of critical assemblies operated in support of the Light Water Breeder Reactor (LWBR) development program at BAPL. A schematic diagram of a side view of the assembly and a top view of a one-sixth symmetric section of the hexagonal seed-blanket core are shown in Figures 2-1 and 2-2, respectively. Tables $2-1$ and $2-2$ contain the pertinent fuel and rod dimensions and components.

The seed rods were spaced on a $0.8202 \mathrm{~cm}$ triangular pitch. What would have been the central seven rods of the seed consisted of a zircaloy-4 pipe $1.905 \mathrm{~cm} 00$ with a $0.094 \mathrm{~cm}$ wall thickness. The pipe contained a solid $1.65 \mathrm{~cm}$ diameter zircaloy-4 plug. The $0.033 \mathrm{~cm}$ gap between the plug and pipe was assumed to be filled with water.

The control rod channel between the seed and blanket was formed by two zircaloy-4 hexagonal cans each $0.3175 \mathrm{~cm}$ thick with a $0.3175 \mathrm{~cm}$ water gap between them. The core was operated with the hafnium control rods $60.1 \mathrm{~cm}$ above the bottom of the sced, and at a temperature of $28.1^{\circ} \mathrm{C}$.

The $\mathrm{ThO}_{2}$ blanket rods were spaced on a $1.7681 \mathrm{~cm}$ triangular pitch, and formed a symmetric hexagon around the control rod channel. The assembly was placed at the center of a $229 \mathrm{~cm}$ diameter stainless steel tank filled with deionized water.

Table 2-3 compares absorption and volume fractions for the BMU-1A with the same quantities obtained by averaging. the values for a representative steam and a representative water cooled hybrid (DTHR) blanket. It can be seen that the values are comparable, so that the BMU-1A experiment provides a reasonable. benchmark for the Vitamin C library in water (as liquid or steam) cooled hybrid fusion blankets. 


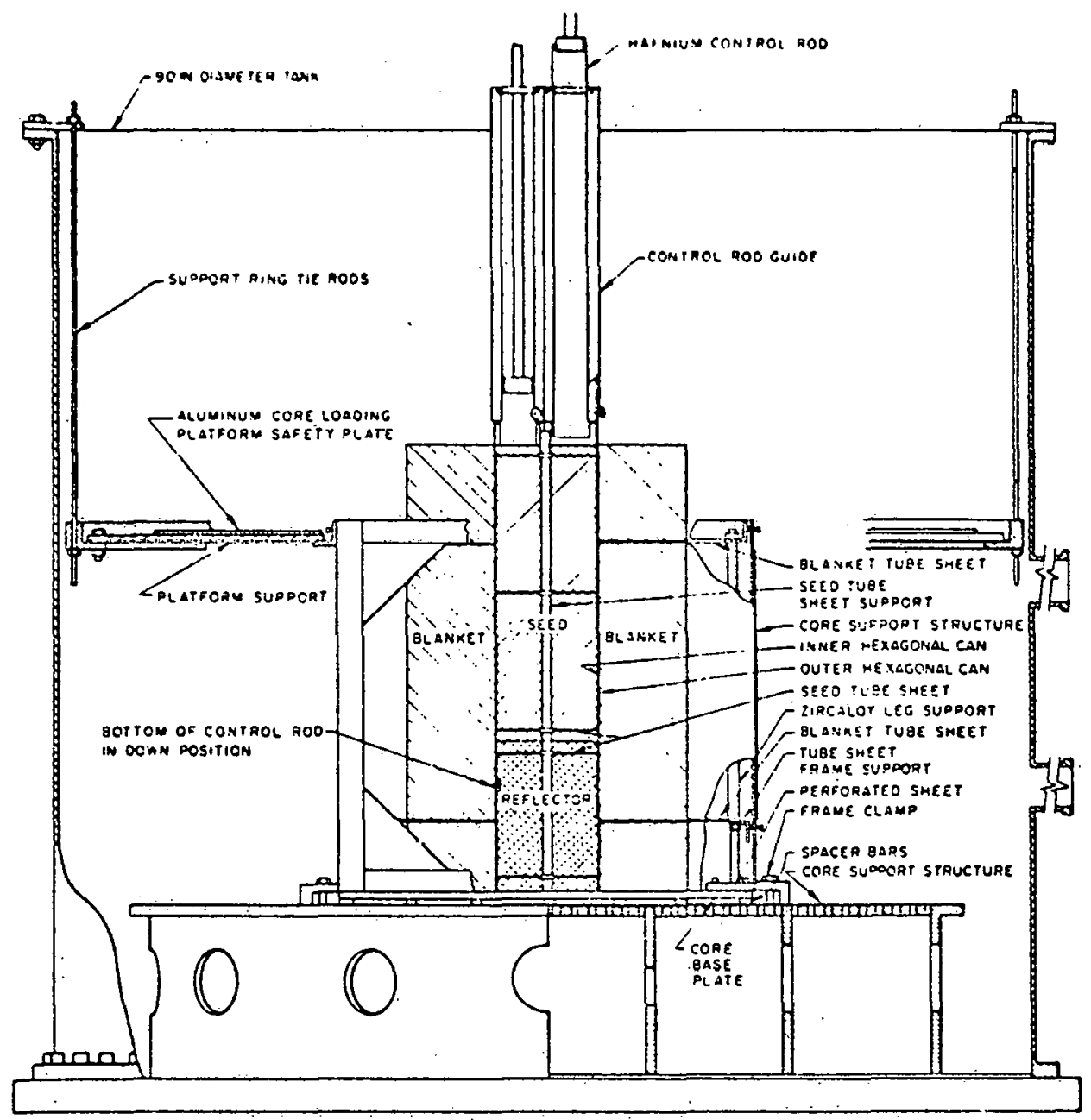

Figure 2-1. BMU-1 Side View. 


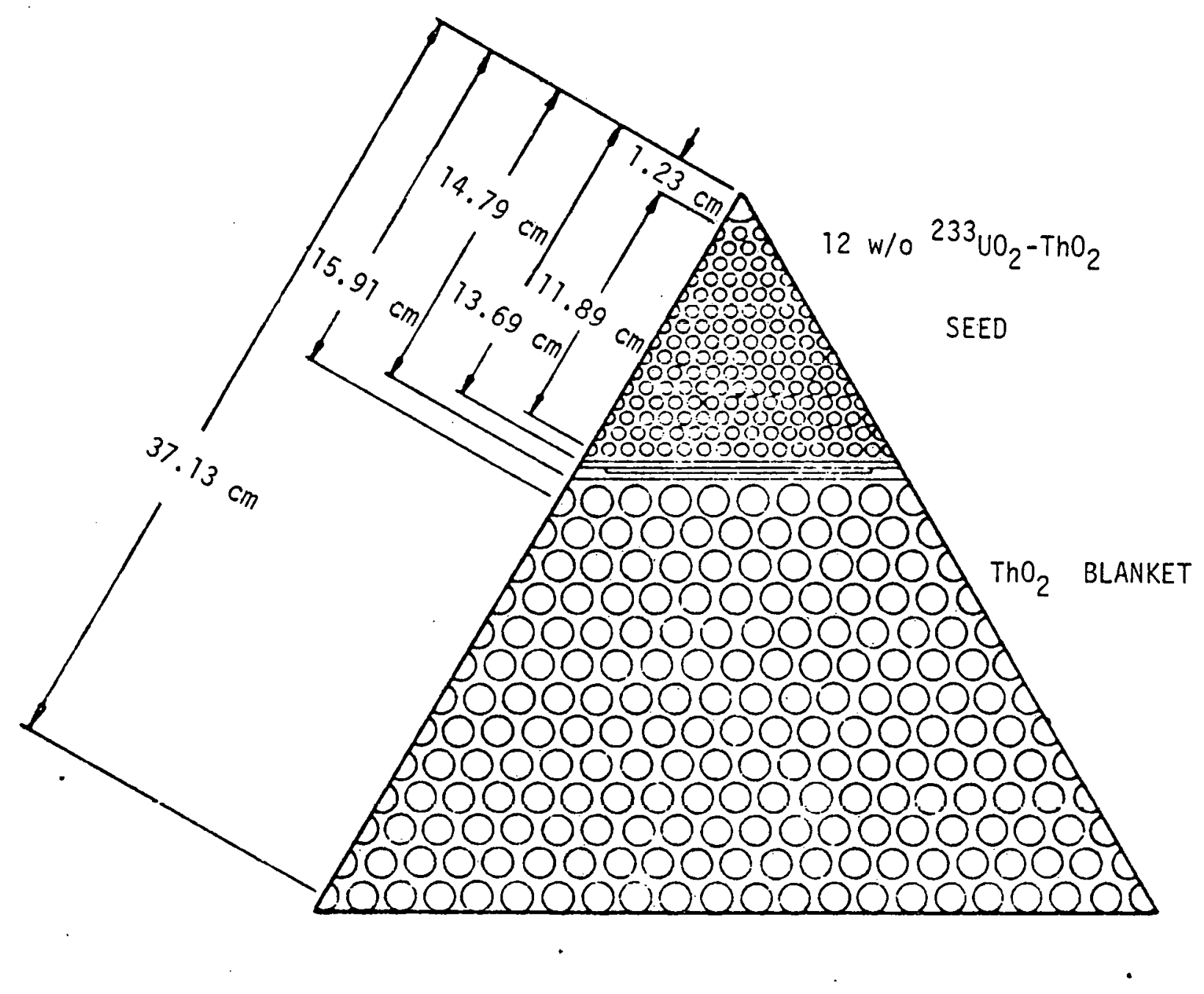

Figure 2-2, BMU-1A One-Sixth Core Top View. 
TABLE 2-1

BMU-1A PELLET AND ROD DIMENSIONS

$\begin{array}{lcccccc} & \begin{array}{c}\text { FUEL } \\ \text { STACK } \\ \text { LENGTH }\end{array} & \begin{array}{c}\text { ROD } \\ \text { LENGTH }\end{array} & \text { ROD OD } & \text { ROD ID } & \begin{array}{c}\text { PELLET } \\ \text { DIAMETER }\end{array} \\ 12 \mathrm{w} / \mathrm{O} \text { SEED } & 70.61 & 71.53 & 0.6365 & 0.5412 & 0.5237 \\ \mathrm{ThO}_{2} \text { BLANKET } & 106.7 & 107.8 & 1.590 & 1.405 & 1.389\end{array}$

ALL DIMENSIONS IN $\mathrm{cm}$ 


\section{TABLE 2-2}

BMU-TA FUEL ROD COMPOSITIONS

$\begin{array}{lcc} & \begin{array}{c}\text { FUEL DENSITY } \\ \mathrm{g} / \mathrm{cm}^{3}\end{array} & \begin{array}{c}\mathrm{UO}_{2} \\ \mathrm{w} / \mathrm{O}\end{array} \\ & 8.387 & 11.79 \\ \mathrm{ThO}_{2} \text { BLANKET } & 9.376 & -\end{array}$

ISOTOPIC COMPOSITION OF THE URANIUM FUEL (ATOM PERCENT)

$\frac{233_{U}}{98.1198} \quad \frac{2.34_{U}}{0.8595} \quad \frac{235_{U}}{0.0268} \quad \frac{2.38_{U}}{0.9939}$


TABLE 2-3

COMPARISON OF DTHR $(3,4)$ AND BMU-1A

VOLUME FRACTIONS

$\begin{array}{lccc} & \text { DTHR* } & & \text { BMU-1A** } \\ \mathrm{H}_{2} \mathrm{O} & 34 \% & 36 \% \\ \text { FUEL } & 46 \% & 47 \% \\ \text { CLAD } & 19 \% & 16 \% \\ \text { VOID } & 1 \% & 1 \%\end{array}$

* Average of steam and water-cooled systems ${ }^{\star \star}$ Seed and blanket average

\begin{tabular}{|c|c|c|}
\hline & ABSORPTION & FRACTIONS* \\
\hline & DTHR $^{\star \star}$ & $B M U-7 A$ \\
\hline $\begin{array}{l}\text { THERMAL } \\
(E<0.4 \mathrm{eV})\end{array}$ & $48 \%$ & $41 \%$ \\
\hline $\begin{array}{l}\text { RESOLVED RESONANCE } \\
(0.4 \mathrm{eV}<\mathrm{E}<5.5 \mathrm{keV})\end{array}$ & $30 \%$ & $44 \%$ \\
\hline
\end{tabular}

\footnotetext{
* For the entire systems

** Average of steam and water-cooled systems
} 


\subsection{CALCULATIONAL MODEL}

\subsection{CROSS SECTION GENERATION}

A flow chart showing all of the AMPX $(1,7)$ modules used to generate the 27 group self-shielded cross sections for each of the four core regions is shown in Figure 3-1. The 27 energy group structure is listed in Table 3-1. The following is a brief description of each of these cylindrical geometry, infinite array, calculations.

\subsubsection{SEED REGION}

A symmetric three rod seed group is shown in Figure 3-2, along with a detail of the cell configuration and dimensions. The radius of the water annulus was calculated to provide the correct water volume fraction for the rod group. The zircaloy 4 clad was simulated by combining zirconium and tin in the correct proportions (Appendix $E$ of Reference 6 ).

\subsubsection{BLANKET REGION}

Except for dimensional changes, the blanket geometry was the same as that for the seed, and is shown in Figure 3-3.

\subsubsection{INNER AND OUTER METAL WATER REGIONS}

The inner metal water region was the zircaloy-4 pipe and plug assembly in the center of the core, while the outer region was the control rod channel between the seed and blanket. The cross sections for the materials in these regions were obtained using the simulated full core geometry shown in figure 3-4. The components consisted of volume smeared number densities. This is a satisfactory procedure since the number of neutrons absorbed in these two metal water regions account for less than $1 \%$ of the total absorption rate. 


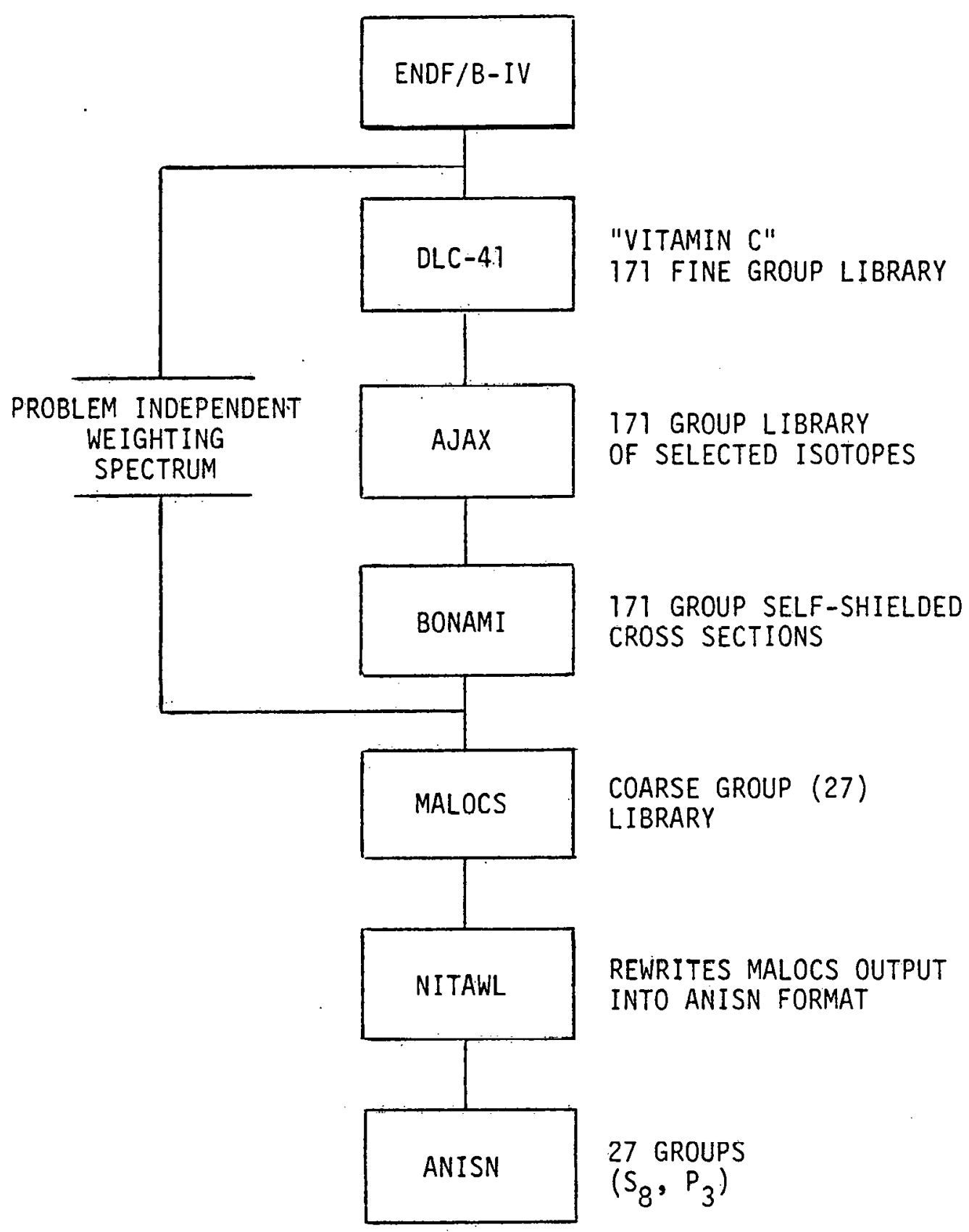

Figure 3-1. Calculational Model. 
TABLE 3-1

27 ENERGY GROUP STRUCTURE

\begin{tabular}{|c|c|c|}
\hline GROUP & $E_{U}(e V)$ & $E_{L}(e V)$ \\
\hline $\begin{array}{r}1 \\
2 \\
3 \\
4 \\
5 \\
6 \\
7 \\
8 \\
9 \\
10 \\
11 \\
12 \\
13 \\
14 \\
15 \\
16\end{array}$ & $\begin{array}{l}1.492+7 \\
1.350+7 \\
1.221+7 \\
1.000+7 \\
7.408+6 \\
5.488+6 \\
3.679+6 \\
2.231+6 \\
1.353+6 \\
8.208+5 \\
4.979+5 \\
3.020+5 \\
1.832+5 \\
1.111+5 \\
4.087+4 \\
1.503+4\end{array}$ & $\begin{array}{l}1.350+7 \\
1.221+7 \\
1.000+7 \\
7.408+6 \\
5.488+6 \\
3.679+6 \\
2.231+6 \\
1.353+6 \\
8.208+5 \\
4.979+5 \\
3.020+5 \\
1.832+5 \\
1.111+5 \\
4.087+4 \\
1.503+4 \\
5.531+3\end{array}$ \\
\hline $\begin{array}{l}17 \\
18 \\
19 \\
20 \\
21 \\
22 \\
23 \\
24 \\
25\end{array}$ & $\begin{array}{l}5.531+3 \\
2.035+3 \\
7.485+3 \\
2.754+2 \\
1.013+2 \\
3.727+1 \\
1.371+1 \\
5.044 \\
1.855\end{array}$ & $\begin{array}{l}2.035+3 \\
7.485+3 \\
2.754+3 \\
1.013+2 \\
3.727+2 \\
1.371+1 \\
5.044 \\
1.855 \\
6.826-.1\end{array}$ \\
\hline $\begin{array}{l}26 \\
27\end{array}$ & $\begin{array}{l}6.826-1 \\
4.140-1\end{array}$ & $\begin{array}{l}4.140-1 \\
1-5\end{array}$ \\
\hline
\end{tabular}




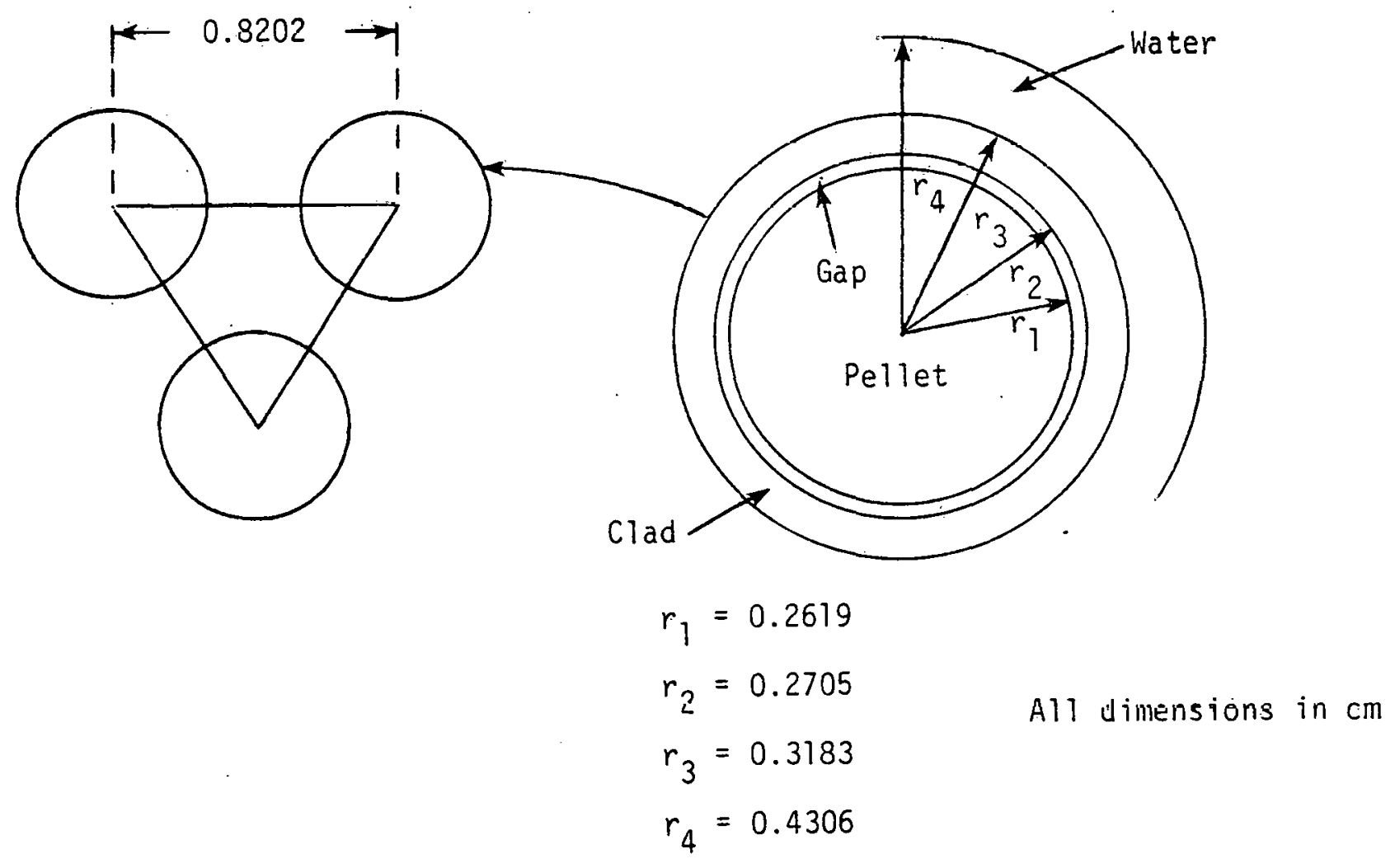

Figure 3-2. Seed Rod Group. 


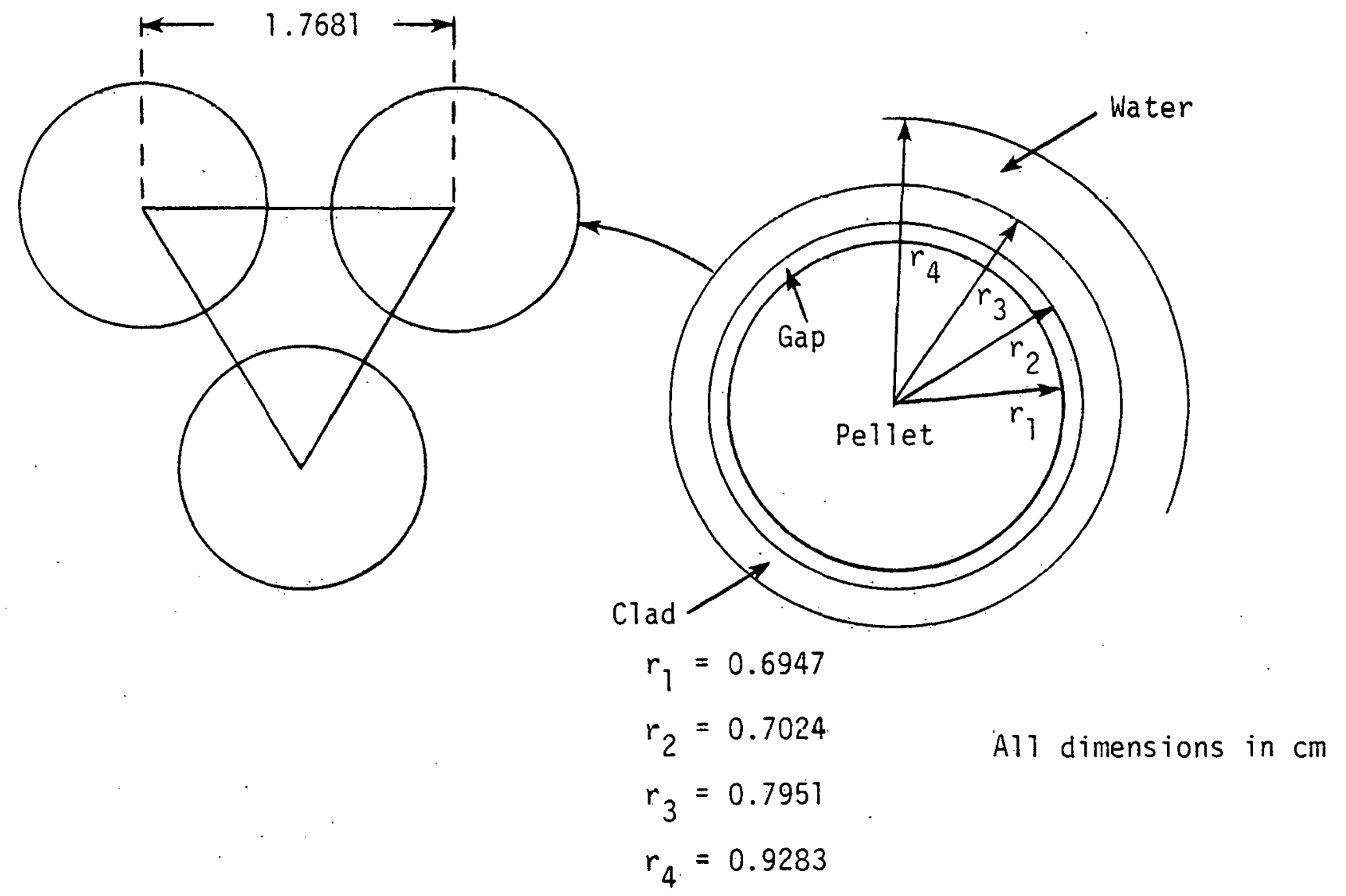

Figure 3-3. Blanket Rod Group 


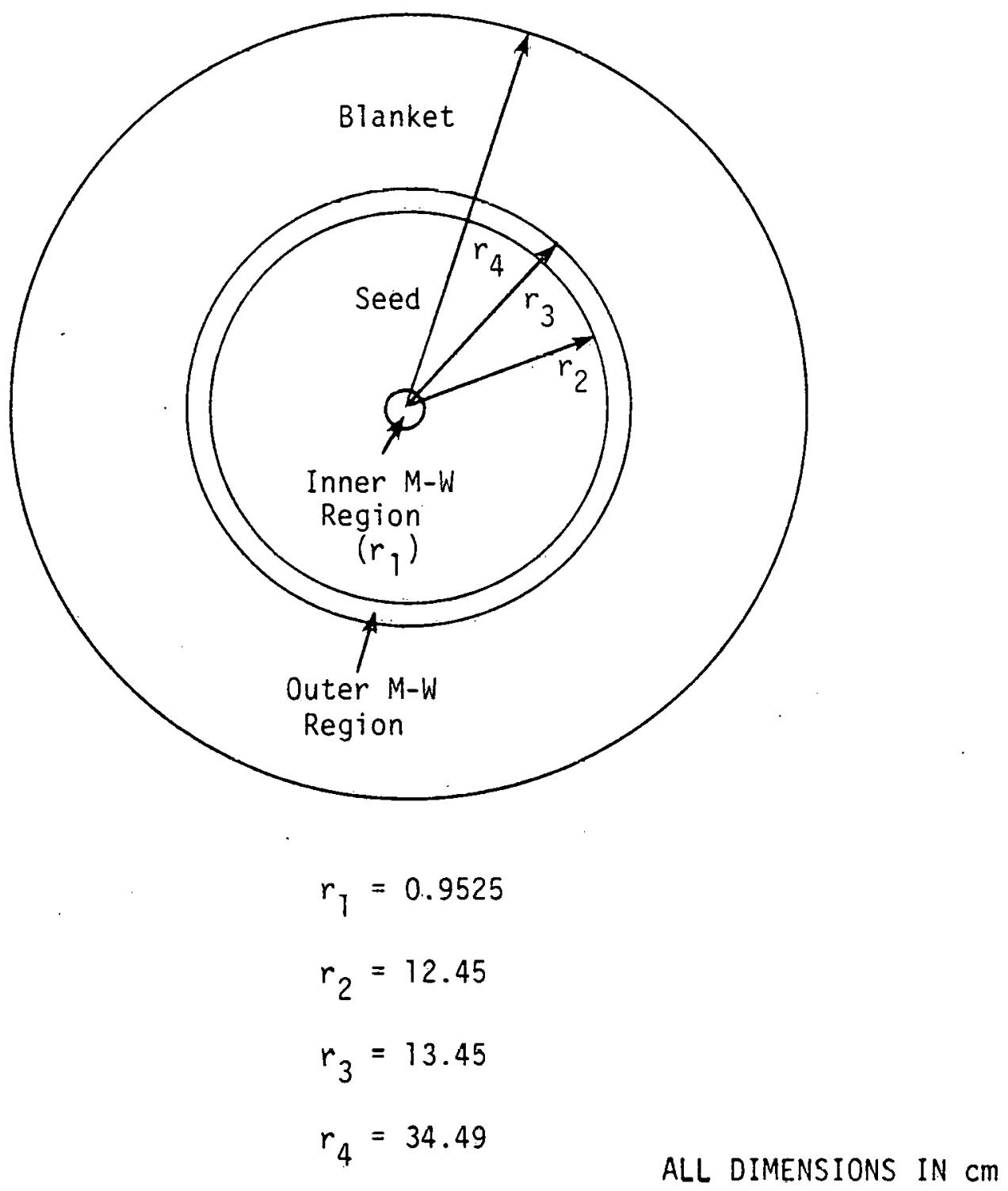

Figure 3-4. Simulated Full Core Geometry. 


\subsection{TRANSPORT CALCULATION}

The ANISN ${ }^{(7)}$ code was run in $P_{3}$ order angular flux expansion and $S_{8}$ order angular quadrature. This combination is commonly used in $14 \mathrm{MeV}$ neutron source transport calculations. The $1 / 6$ symmetric core region was shown in Figure 2-2; the cylindricized equivalent is the same as that shown in Figure 3-4 except for an outer water region approximately $12 \mathrm{~cm}$ thick to provide the correct radial boundary condition. Axial leakage was accounted for using the experimental buckling measured with ${ }^{235} U$ wires. Since the buckling was found to be radially constant within experimental uncertainty, an energy independent weighted average value of $14.40 \times 10^{-4} \mathrm{~cm}^{2}$ was input into the program.

The fission spectrum was assumed to be Maxwellian in shape, with a "temperature" of $1.33 \mathrm{MeV}$. The uncertainty introduced by this assumption (shape and average energy of the fission spectrum) for the BMU-1A core was estimated to be about $0.3 \%$ in $k_{\text {eff }}$. The unnormalized flux in group $g$ was then calculated from the expression:

$$
\begin{aligned}
\phi_{g}=\int_{E_{g-1} .}^{E_{g} \sqrt{E} e^{-E / T}}=T \sqrt{E_{g-1}} e^{-E_{g-1} / T}-T \sqrt{E_{g}} e^{-E_{g} / T} \\
+\frac{T}{2} \sqrt{\pi T}\left\{\operatorname{erf} \sqrt{\left.\frac{E_{g}}{T}-\operatorname{erf} \sqrt{\frac{E_{g-1}}{T}}\right\},}\right.
\end{aligned}
$$

where erf denotes the usual error function. 


\subsection{RESULTS}

\subsection{CORE EIGENVALUE}

One of the most important factors characterizing the neutronics behavior of a hybrid blanket is its neutron multiplication. Both fissile and power production are very sensitive to this parameter. It is desirable, therefore, to have some assurance that the calculational model is able to predict blanket eigenvalues with reasonable accuracy. This is also important from a criticality safety viewpoint for blanket eigenvalues approaching unity.

The eigenvalue obtained for the BMU-IA from the ANISN calculation and the Vitamin $C$ derived library described earlier was

$$
k_{\text {eff }}=1.0238
$$

Several input parameters affect this value, and these were investigated.

\subsubsection{MESH SPACING}

The mesh spacings in the problem were $0.3183 \mathrm{~cm}$ in the seed and $0.7349 \mathrm{~cm}$ in the blanket. Doubling this spacing changed $k_{\text {eff }}$ by only $0.2 \%$ so that the spacing used is considered adequate.

\section{1 .2 INPUT BUCKLING}

The calculated eigenvalue for this leaky core was found to be sensitive to the input buckling, with a value of 1.0824 for the zero buckled core. Therefore, the energy and spatially constant buckling description in the calculation, obtained experimentally with ${ }^{235} \mathrm{U}$ wires, introduces some uncertainty into the calculation of eigenvalue. 


\section{1 .3 GEOMETRY}

The seed radius in the cylindrical calculation was found to strongly affect $k_{\text {eff }}$, with a sensitivity of about $5 \%$ per $\mathrm{cm}$. Therefore, dimensional errors, as well as conversion of the hexagonal core geometry into volume equivalent cylinders, introduces some additional uncertainty into the calculated result.

\section{1 .4 FISSION SPECTRUM}

The fission spectrum used was a Maxwellian with an average energy of $1.995 \mathrm{MeV}$. The estimated uncertainty in this value is $\pm 30 \mathrm{keV}$. The sensitivity of the BMU-IA eigenvalue to fission spectrum average energy was found to be approximately $0.01 \% / \mathrm{keV}$. The uncertainty introduced into the calculated eigenvalue is therefore $0.3 \%$.

The total uncertainty introduced by the various problem input parameters considered above is estimated to be about $1 \%$ in $k_{\text {eff }}$, so that

$$
k_{\text {eff }} \text { (calculated) } \cong 1.02 \pm 0.01 \text {. }
$$

\subsection{CORE ACTIVATION SHAPES}

Experimental core activation shapes were obtained by locating a series of foils at a common height, one in each of a number of fuel rods, and then $\gamma$-counting the appropriate activity. The height was chosen to be in the center of the fuel zones, far from any grids or tube sheets. The reactions measured were ${ }^{233} \mathrm{U}$ fission, ${ }^{232}$ Th fission and capture, and dysprosium (Dy) capture. This last was not considered here, since Dy is not included in the Vitamin C library.

The calculated activation shapes were obtained directly from ANISN edits, with the intervals chosen to correspond to actual rod locations. A trace amount of ${ }^{233} U$ was included in the blanket so that its fission rate could be computed in this ${ }^{233} U$ free zone. It was necessary to normalize for the differences in number densities of both ${ }^{233} \mathrm{U}$ and ${ }^{232} \mathrm{Th}$ in the seed and blanket, since the experimental data is provided in terms of normalized activations per foil atom, while the calculated activation rates are given per $\mathrm{cm}^{3}$ in the appropriate interval. 
The comparisons of measurement and calculation are summarized in Figures 5-1, 5-2 and 5-3, where the ratio of measurement/calculation (M/C) has been plotted for each of the reactions as a function of distance from the core center. In all cases normalization was performed at the interior points, i.e., at those points not adjacent to boundaries. The solid curves were included to serve only as eye-guides, and are not fits to the data points.

Examining first the ${ }^{233} \mathrm{U}$ fission results, Figure $5-1$, it can be seen that at the interior points $M / C$ is within about $\pm 5 \%$, with the average value just over $2 \%$. However, near the boundaries of the metal-water regions the calculation greatly underpredicts the ${ }^{233} \mathrm{U}$ fission rate with the discrepancy as large as $24 \%$. Since the fission is primarily thermal, this indicates that the calculation is underpredicting the thermal flux in these regions. This is probably a consequence of the thermal group cross section treatment. Virtually the same shapes were observed when the mesh spacing was doubled.

The results for ${ }^{232} \mathrm{Th}$ capture, in Figure 5-2, are seen to be similar, with good agreement again at the interior points $( \pm 6 \%$ ), rising to a maximum discrepancy of about $15 \%$ near the control rod channel. This is smaller than that observed for $233 \mathrm{U}$ fission, probably due to the lower epithermal/thermal fission ratio of $233 \mathrm{U}$ compared to the epithermal/thermal capture ratio for thorium ( $p 48$ Ref. 6 ).

If the peaking observed near the metal/water boundaries is indeed a thermal flux problem, it should not appear in the thorium fast fission traverse. That this is indeed the case is apparent from Figure 5-3. The ratio shape is seen here to vary slowly through the seed and blanket, with the fission rate calculated in the blanket too high compared to that in the seed. However, this may be due to some difficulty in the experimental data. Reference 6 has two sets of thorium fission data, one a traverse to the flat of the hexagonal seed and blanket, and the other a traverse to the corner. The two sets of data are not consistent. The corner data has been used here, since the Bettis group made calculational comparisons to this data only. Nonetheless, the experimental data are suspect and the $\pm 15 \%$ variation in $M / C$ may not be real. 
$\odot$ DATA POINTS

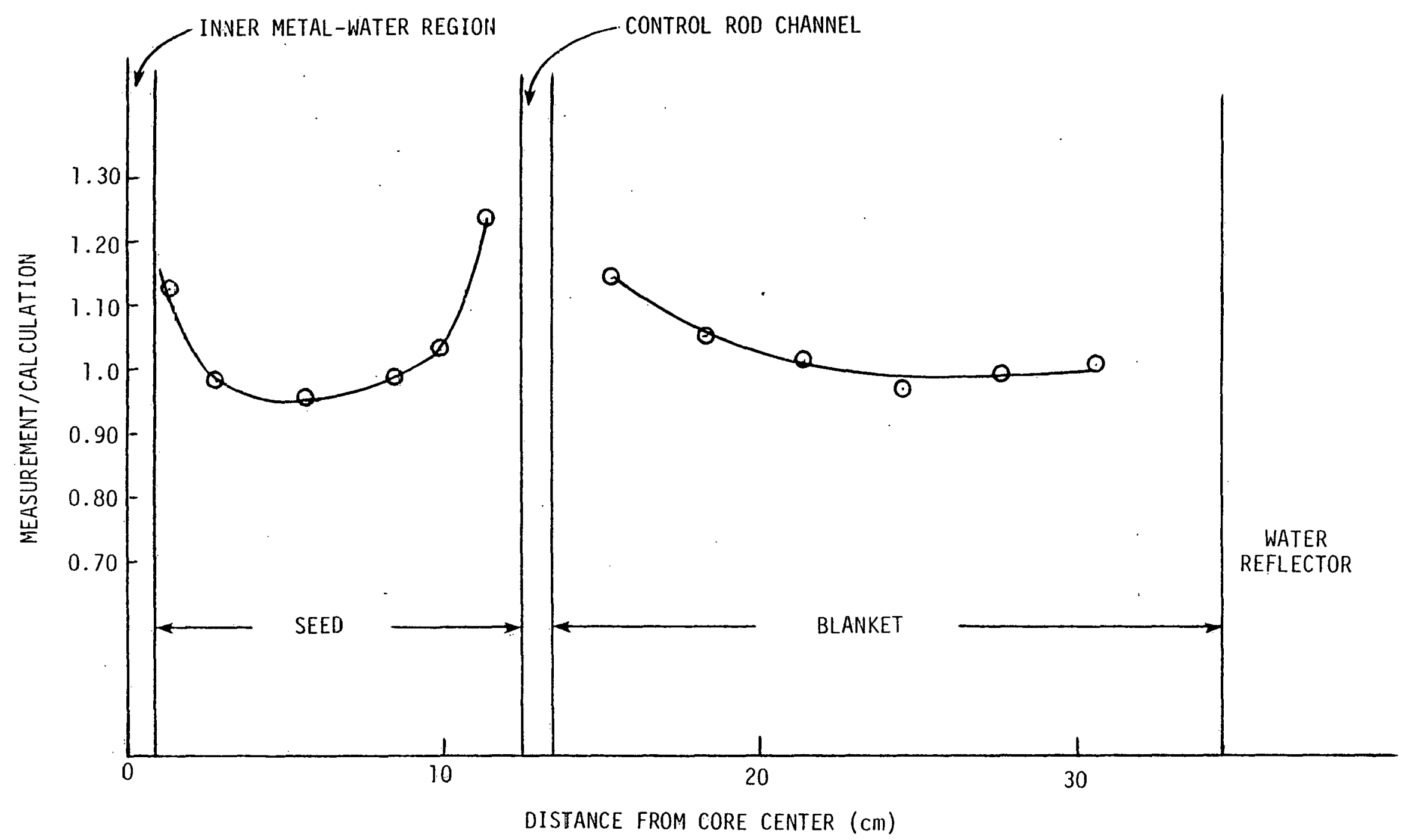

Figure 5-1. Comparison of Measurement and Calculation for ${ }^{233} \mathrm{U}$ Fission. 


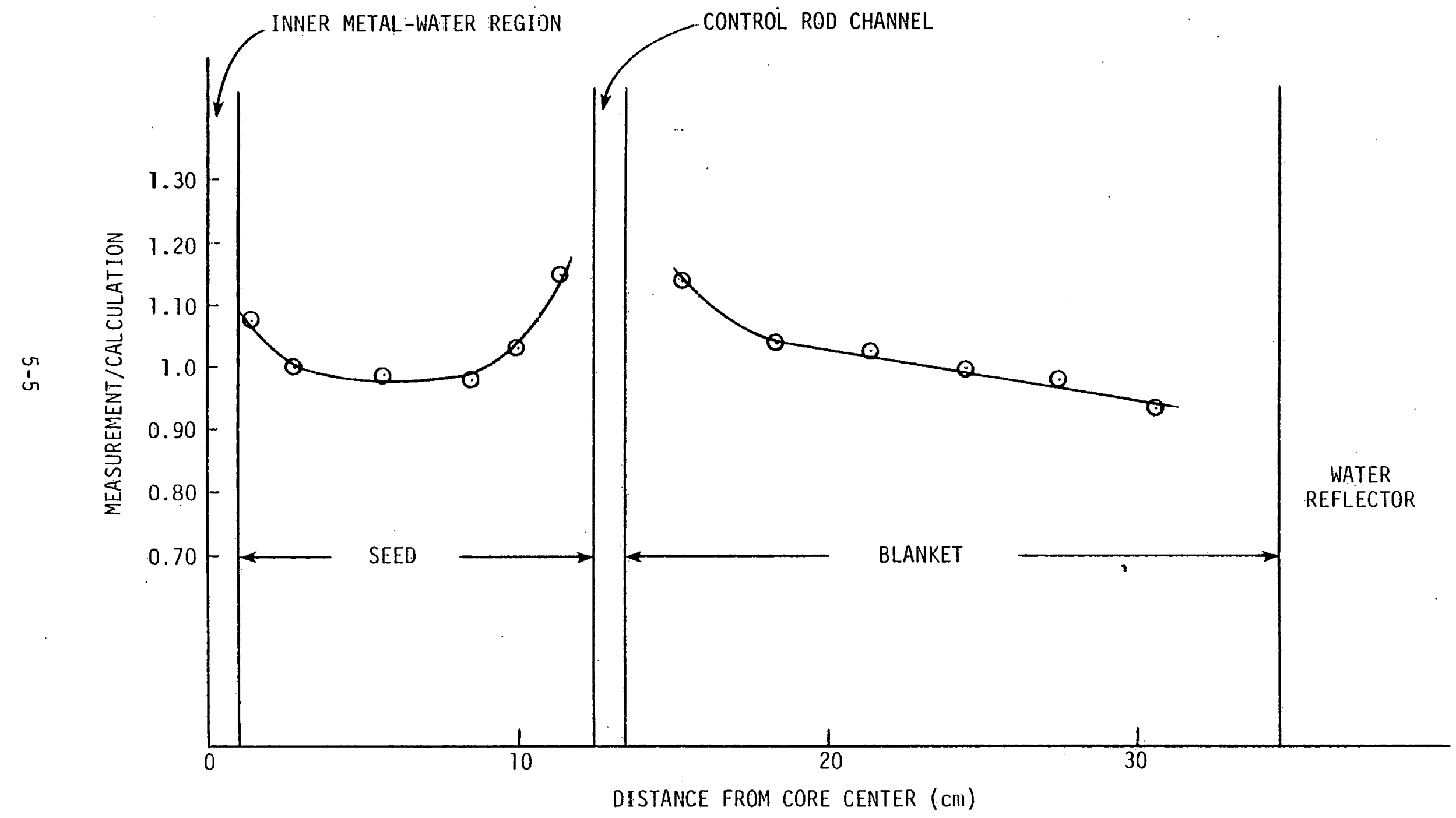

Figure 5-2. Comparison of Measurement and Calculation for Thorium Capture. 
THORIUM FISSION

$\odot$ DATA POINTS

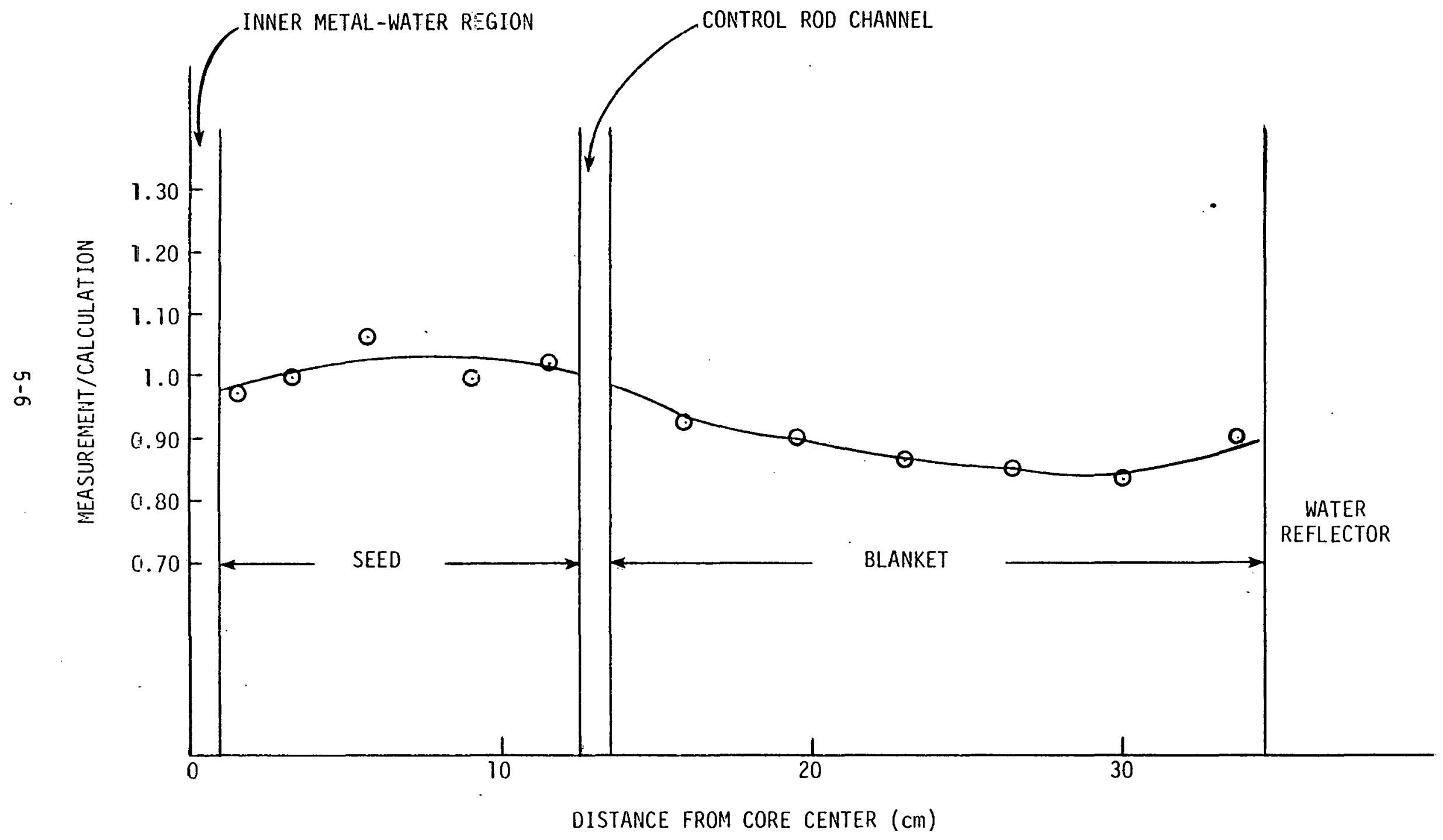

Figure 5-3. Comparison of Measurement and Calculation for Thorium Fission. 


\subsection{SUMMARY AND CONCLUSIONS}

A tightly packed water moderated ${ }^{233} \mathrm{UO}_{2}-\mathrm{ThO}_{2}$ critical assembly was analyzed utilizing the Vitamin $C$ library and the $1-D$, Sn code, ANISN $\left(P_{3}, S_{8}\right)$. The 27 few-group self-shielded cross sections were derived from Vitamin $C$ using standard AMPX modules. This is a neutronics model currently being used in scoping analyses of fusion-fission hybrid blankets containing water (steam or liquid) as coolant. The purpose of this study was to provide some validation of the model as applied to such systems.

The quantities compared were the core eigenvalue and various activation shapes. The calculated eigenvalue was $1.02 \pm 0.01$, where the uncertainty is an estimate of the possible error introduced by some of the input data (axial buckling, seed and blanket dimensions, fission spectrum mean energy). Agreement. with the experimental value $(1.0)$ is considered adequate for the scoping nature of the model applications.

The ${ }^{233} \mathrm{U}$ fission and ${ }^{232}$ Th capture shapes. through the seed and blanket of the core were found to agree within about $\pm 5 \%$ of experiment, except near the water-metal boundaries where large (up to $24 \%$ ) differences were observed. This was ascribed to an underestimation of the thermal group flux resulting from the lack of an adequate thermal cross section treatment in the model. This hypothesis was supported by the absence of such error peaking in the thorium fast fission shape comparison. Therefore, while the model appears to provide good volume averaged reaction rates, care must be exercised near water boundaries, especially for thermal-hydraulic applications where heating rates may be significantly underestimated.

While not showing any error peaking, the thorium fast fission level calculated in the blanket, compared to the seed, appears to be significantly high. However, there may be some difficulty in the experimental data, and it is not clear if this is real. 


\subsection{REFERENCES}

1. R. W. Roussin, C. R. Weisbin, J. E. White, M. M. Greene, R. Q. Wright, and J. B. Wright, "The CTR Processed Multigroup Cross Section Library," ORNL/RSIC-37 (1976).

2. D. Garber, compiler, "ENDF-201, ENDF/B Summary Documentation," BNL-17541 (ENDF-201) (1975).

3. D. L. Chapin, J. W. H. Chi, and J. L. Kelly, "Evaluation of Potential Blanket Concepts for a Demonstration Tokamak Hybrid Reactor, "Proceedings of the Third Topical Conference on the Technology of Controlled Nuclear Fusion (May 1978) (to be published).

4. E. Greenspan, A. Schneider, A. Misolovin, D. Gilai, and P. Levin, "Natural Uranium Fueled Light Water Moderated Breeding Hybrid Power Reactors - A Feasibility Study," PPPL-1444, Princeton University Plasma Physics Lab. (1978).

5. J. W. H. Chi, D. L. Chapin, T. Prevenslik, and J. L. Kelly, An Evaluation of Steam and Boiling Water Cooled DTHR Blanket Concepts," Iransactions American Nuclear Society, 30, 52 (1978).

6. J. A. Mitchell (ed.), "BMU Series of ${ }^{232}$ U Fueled Critical Experiments," WAPD-TM-1117, Bettis Atomic Power Laboratory (1975).

7. W. W. Engle, Jr., "A Users Manual for ANISN," Oak Ridge Gaseous Diffusion Plant Report K-1693 (1967).

8. N. M. Greene, et al., "AMPX: A Modular Code System for Generating Coupled Multigroup Neutron-Gamma Libraries from ENDF/B," ORNL/TM-3706 (1976). 